\title{
Contribution to the Analysis of the Volatile Constituents from some Lavender and Lavandin Cultivars Grown in Greece
}

\author{
Paschalina S. Chatzopoulou and Apostolos H. Goliaris \\ National Agricultural Research Foundation (NAGREF), Agricultural Research Centre of Macedonia \& Thrace, \\ Department of Aromatic and Medicinal Plants, P.O. Box 60458, Thermi 57001, Thessaloniki, Greece \\ e-mail: xatzlin@yahoo.gr
}

\section{S. T. Katsiotis*}

Department of Pharmaceutics, School of Pharmacy, Aristotle University of Thessaloniki, 54124, P.O. Box 1589, Thessaloniki, Greece, e-mail: stakat@pharm.auth.gr

The essential oils of Lavandula angustifolia and the Lavandin hybrids "super" and "special" grown in Greece, were studied in order to evaluate their quality as far as the correlation of their essential oil composition. The essential oil yields were determined to $4.4 \%, 7.5 \%$ and $8.5 \%$ in the lavandula and lavandin "super" and "special" hybrids respectively. Fifty-nine constituents were identified representing the $99 \%$ of the oils. The qualitative analysis of the oils was carried out by GC/MS and revealed that linalool and linalylacetate were the predominant constituents. Remarkable differences were noticed between the camphor percentages among them $(11.35 \%$ and $5.03 \%$ for the "super" and "special" respectively).

Keywords: Lavandula angustifolia, Lavandin, essential oil yield, GC/MS analysis, linalool, linalylacetate

\section{Introduction}

Interest in growing lavender has taken an upsurge in the past ten years, with the old-fashioned lavender fragrance becoming popular again, perhaps because of its use in aromatherapy'. Essential oil of lavender is also used as flavoring for various foods and beverages, though non-food products manufactured with lavender oil include soaps, colognes, and other cosmetics. Lavender may be grown as bedding plant, herb specimen, tea plant, bee forage, or source of fragrance in landscaping designs.

Lavender is a popular aromatic and perennial Mediterranean herb, belonging to Lamiaceae family, growing almost all over the world Asia, America, Australia, and almost all over Europe. It is marked as the fresh or dried plant.

Among the Lavender species, Lavandula angustifolia Mill. produces the best quality's essential oil for the industry, and due to the high linalool content, it is used in the aromatherapy for its mild sedative activity as well as in antibacterial and antifungal medicaments ${ }^{2,3}$. It is also reported in the folk medicine $e^{4}$ because of the carminative, diuretic and stomachic properties. Very high-quality essential oil of lavender is required for use in the alternative health practice of aromatherapy, as far as in pharmaceutics.

Lavandin oils are distilled from hybridized plant Lavandula hybrida Reverchon, a cross between Lavandula angustifolia Mill. and Lavandula latifolia Medic. Lavandin plants are vigorous and extremely productive, though their essential oils yield can be 2-3 times higher compared with $L$. angustifolia ${ }^{5}$. They produce high yields of lower quality and priced lavender oils, used widely in the 
production of inexpensive perfumes, soaps, bath products, detergents etc., or in the adulteration of the high priced lavender oils ${ }^{6}$. There are many successful commercial hybrids, the most of France origin, cultivated in many parts of Europe, among them the best known are "abrialis", "super", and "grosso".

In Greece, lavender is growing in many areas and cultivated in several districts but not systematically. Because of the great commercial interest of lavender oils the aim of the present work was to study the essential oil of a) Lavandula angustifolia Mill. grown in Northern Greece, though as far it concerns to our knowledge, there are no reported data on the Greek oil and b) the essential oils of two commercial Lavandin hybrids cultivated in Greece, the "super" and "special".

\section{Results and Discussion}

The distillation of L. angustifolia Mill. and of super and special Lavandin hybrids yielded pale yellow essential oils, which percentage yields' were determined as $4.4 \%, 7.5 \%$, and $8.5 \%$ respectively. These yields are classified to the highest reported in the literature for Lavender oils ${ }^{7,8,9}$. The yields of the hybrids were significantly higher than those of $L$. angustifolia, the special hybrid being more efficient than the super one $(93 \%$ and $70 \%$ higher yields, respectively, compared to $L$. angustifolia).

In the qualy-quantitative analysis of the oils, performed by GC and GC-MS, were detected more than eighty constituents and fifty-nine of them were identified, representing at least the $99 \%$ of the oils. The percentages reported were based on the data after three chromatographic runs (Srel. \pm 1.01 $- \pm 1.2 \%)$. The constituents were identified by comparing the retention times on three columns of different polarity with those of authentic samples using the peak enrichment technique. For compounds that pure samples were not available, identification was carried out by comparison with references oils and mainly by mass spectrometry, matching the peak mass spectra to those of NIST 98 mass spectra library, and of the commercial library Newterp for essential oils ${ }^{10}$.

In Table 1 are listed the identified constituents of lavender, and of super and special lavandin hybrids respectively. Although the number of components of lavender essential oil resulted high, the main components $(>1 \%)$ representing the $91.54 \%$ of the total sample, were eleven - linalool $(50.63 \%)$, linalylacetate $(15.72 \%)$, terpinen-4-ol $(7.84 \%)$, cis-ocimene $(4.25 \%)$, trans-ocimene $(2.73) \%$, lavandulyl-acetate $(2.73 \%), \beta$-caryophyllene $(2.04 \%)$, lavandulol $(1.52 \%), \alpha$-terpineol $(1,52 \%)$, 3-octanone $(1.36 \%)$ and cryptone $(1.2 \%)$. They correspond to the most significant compounds as indicated by extensive studies performed on lavender plants $\mathrm{s}^{11,12,13}$.

The percentage amount of linalool $(50.63 \%)$ is among the highest yields encountered in the literature; $50.52 \%$ was recorded for the cultivars Munsteam grown in the United States ${ }^{12}, 49.90 \%$ for an Italian Lavender sample oil, $49.86 \%$ and $44.44 \%$ for different French cultivars ${ }^{14,15}$. Camphor and 1,8 cineol, which undermine the quality of the oil, accounted for 0.06 and $0.66 \%$ of the oil respectively. Nevertheless, the amounts of terpinen-4-ol, and the typical components for lavender oil, lavandulol and lavandulylacetate were also remarkable.

The oxygenated compounds nerol, nerylacetate, geranylacetate (known as the "rhodinol" part of the oil) that are important for the overall aroma, donating a sweet and pleasant note to the oil, contributed to the lavender oil as well $-1.76 \%$ (Table 2 ).

The super and special lavandin hybrids contained linalool as main component $(23.01 \%$ and $37.69 \%$ respectively), though the linalylacetate content varied from $20.35 \%$ to $29.14 \%$ falling within the ranges of the typical lavandin oils ${ }^{14}$. Significant differences were observed between the super and special hybrids concerning the percentages of 1,8 cineol $(15.85 \%$ and $5.39 \%)$, camphor $(11.35 \%$ and $5.03 \%)$, terpinen-4-ol $(6.67 \%$ and $0.08 \%)$ and those of lavandulylacetate $(0.37 \%$ and $2.2 \%)$ 
respectively. The amounts of camphor and 1,8 cineol of super lavandin essential oil $(11.35 \%$ and $15.85 \%$ respectively) match those noted by Melegari et al. ${ }^{16}$, for Italian super cultivars. In contrast, the camphor and 1,8 cineol were found in lower quantities in the special hybrid $(5.03$ and $5.39 \%$ respectively). Moreover the group of the components constituting of the "rhodinol" part was higher in the special hybrid: $2.92 \%$ versus $2.43 \%$ in the super one (Table 2 ), nevertheless both values were higher than those recorded for known Italian lavandin oils ${ }^{17}$.

In conclusion, Lavender and Lavandin cultivated in Greece produce essential oils with quite high yields (4.4\%, $7.5 \%$, and $8.5 \%)$. Moreover the super and special hybrids show good adaptability to the Greek climate and environmental conditions, the latter producing an essential oil of superior yield and quality.

\section{Experimental}

Plant material

The plant material was originated from experimental fields established in Northern Greece, full sun exposed, with soil conditions; moderate alkaline $\mathrm{PH}$, well drainage and sufficient in all the nutrients. The fields were not irrigated or fertilised, not even any kind of plant protection was applied.

For analysis, samples of lavender and lavandin plants (flowering tops) were collected in July, from the two middle rows (of four rows) of the experimental fields at full bloom stage. Vouchers of the samples investigated are kept at the Herbarium of the Institute of Aromatic and Medicinal plants, NAGREF.

\section{Isolation and yield of the essential oils}

The percentage oil yield was determined using the European Pharmacopoeia apparatus (Clevenger type) after 3 replications (SD $\pm 0.3 \%$ ). The samples of $20 \mathrm{~g}$ of plant material were distilled for 1 hour and $30 \mathrm{~min}$ at distillation rates $3-3.5 \mathrm{ml} / \mathrm{min}^{18}$. The oils were dried over anhydrous $\mathrm{Na}_{2} \mathrm{SO}_{4}$ and stored with $3 \mathrm{ml}$ of $\mathrm{n}$-pentane in sealed glass vials under refrigeration $\left(-20^{\circ} \mathrm{C}\right)$.

\section{Gas Liquid Chromatography and Gas Chromatography / Mass Spectrometry}

The essential oil samples were analysed by gas chromatography, using a Gas Chromatograph Hewlett Packard 5890 Series II, equipped with one injection port and a two-channel system of columns and respective FIDs, connected to a chromatographic integrator (Hewlett Packard 3396 Series II Dual Channel). Sample injection $0.2-0.3 \mu$ l of a $10 \%$ essential oil solution in pentane; split 1:20. Three different polarity fused silica columns were used: a) Durabond - DB 1, b) DBWax both of $60 \mathrm{~m} \times 0.25 \mathrm{~mm}$ i.d., film thickness $0.25 \mu \mathrm{m}$ (J \& W Scientific Inc., Rancho Cordova, California, USA), and c) CP-Sil $19 \mathrm{CB}, 25 \mathrm{~m} \times 0.25 \mathrm{~mm}$ i.d., film thickness $0.20 \mu \mathrm{m}$ (Chrompack Nederland, Middelburg, The Netherlands). Oven temperature: 45 to $220^{\circ} \mathrm{C}$ at $3.5^{\circ} \mathrm{C} / \mathrm{min}$, carrier gas nitrogen at $140 \mathrm{Kpa}$, injection temperature $220^{\circ} \mathrm{C}$, detectors' temperature $300^{\circ} \mathrm{C}$. The percentage compositions were computed from the GC peak areas without correction factors.

The identification of the constituents was carried out 1) using the peak enrichment technique of reference compounds (authentic samples by Roth, Aldrich and Sigma), 2) with the chromatograms comparison to those of essential oils previously analyzed and published from our data bank and 
Table 1. Percentage composition of the volatiles constituents from Lavandula angustifolia and of the hybrids "Super" and "Special" cultivated in Greece

\begin{tabular}{|c|c|c|c|c|c|c|}
\hline $\mathrm{Nr}^{\mathrm{a}}$ & $\mathrm{KI}^{\mathrm{b}}$ & Constituents & $\begin{array}{l}\text { Lavandula } \\
\text { angustifolia }\end{array}$ & "Super" & "Special" & $\begin{array}{l}\text { Method of } \\
\text { Identification }\end{array}$ \\
\hline & & & \multicolumn{3}{|c|}{ Percentage yield } & \\
\hline 1 & 0931 & $\alpha$-Thujene & 0,19 & 0,11 & - & $1,2,3$ \\
\hline 2 & 0939 & $\alpha$-Pinene & 0,24 & 0,68 & 0,19 & $1,2,3$ \\
\hline 3 & 0953 & Camphene & 0,04 & 0,31 & 0,18 & $1,2,3$ \\
\hline 4 & 0976 & Sabinene & 0,10 & 0,38 & 0,10 & $1,2,3$ \\
\hline 5 & 0978 & 1-Octen-3ol & 0,17 & - & 0,04 & $1,2,3$ \\
\hline 6 & 0980 & $\boldsymbol{\beta}$-Pinene & 0,05 & 0,95 & 0,21 & $1,2,3$ \\
\hline 7 & 0986 & 3-Octanone & 1,36 & - & 0,89 & $1,2,3$ \\
\hline 8 & 0991 & $\beta$-Myrcene & 0,61 & 0,99 & 0,91 & $1,2,3$ \\
\hline 9 & 0993 & 3-Octanol & 0,27 & - & 0,09 & $1,2,3$ \\
\hline 10 & 1005 & $\alpha$-Phellandrene & 0,04 & 0,03 & - & $1,2,3$ \\
\hline 11 & 1008 & Hexyl acetate & - & 0,20 & 1,07 & $1,2,3$ \\
\hline 12 & 1011 & $\Delta 3$-Carene & 0,12 & 0,07 & - & $1,2,3$ \\
\hline 13 & 1018 & $\alpha$-Terpinene & - & 0,08 & - & $1,2,3$ \\
\hline 14 & 1026 & p-Cymene & 0,18 & 0,06 & - & $1,2,3$ \\
\hline 15 & 1031 & Limonene & 0,89 & - & - & $1,2,3$ \\
\hline 16 & 1033 & 1,8-Cineole & 0,66 & 15,85 & 5,39 & $1,2,3$ \\
\hline 17 & 1040 & cis-Ocimene & 4,25 & 2,67 & 1,35 & $1,2,3$ \\
\hline 18 & 1050 & trans-Ocimene & 2,73 & 1,90 & 2,08 & 2,3 \\
\hline 19 & 1062 & $\gamma$-Terpinene & 0,16 & 0,25 & - & $1,2,3$ \\
\hline 20 & 1068 & cis-Sabinene hydrate & - & - & 0,06 & 2,3 \\
\hline 21 & 1064 & cis-Linalool oxide & - & - & 0,08 & $1,2,3$ \\
\hline 22 & 1088 & Terpinolene & - & 0,33 & 0,28 & $1,2,3$ \\
\hline 23 & 1097 & trans-Sabinene hydrate & - & 0,34 & - & 2,3 \\
\hline 24 & 1098 & Linalool & 50,63 & 23,01 & 37,69 & $1,2,3$ \\
\hline 25 & & Propionic acid hexyl est. & - & 0,13 & 0,15 & $1,2,3$ \\
\hline 26 & 1110 & Octen-3-yl-acetate & 0,10 & - & 0,30 & $1,2,3$ \\
\hline 27 & 1124 & 3-Octanol acetate & - & - & 0,12 & 2,3 \\
\hline 28 & 1129 & allo-Ocimene & 0,02 & - & - & $1,2,3$ \\
\hline 29 & 1143 & Camphor & 0,06 & 11,35 & 5,03 & $1,2,3$ \\
\hline 30 & 1150 & Hexyl isobutyrate & - & 0,17 & 0,17 & $1,2,3$ \\
\hline 31 & 1165 & Borneol & 0,34 & 1,29 & 1,71 & $1,2,3$ \\
\hline 32 & 1166 & Lavandulol & 1,52 & - & 0,14 & $1,2,3$ \\
\hline 33 & 1177 & Terpinen-4-ol & 7,84 & 6,67 & 0,08 & $1,2,3$ \\
\hline 34 & & Cryptone1 & 1,20 & 0,28 & 0,22 & 2,3 \\
\hline 35 & 1189 & $\alpha$-Terpineol & 1,52 & 3,81 & 2,91 & $1,2,3$ \\
\hline 36 & 1191 & Hexyl butyrate & - & 0,69 & 0,82 & $1,2,3$ \\
\hline
\end{tabular}




\begin{tabular}{|c|c|c|c|c|c|c|}
\hline $\mathrm{Nr}$ & KI & Constituents & $\begin{array}{l}\text { Lavandula } \\
\text { angustifolia }\end{array}$ & "Super" & "Special" & $\begin{array}{l}\text { Method of } \\
\text { dentification }\end{array}$ \\
\hline & & & \multicolumn{3}{|c|}{ Percentage yield } & \\
\hline 37 & 1211 & 1-Octanol acetate & - & 0,05 & 0,06 & 2,3 \\
\hline 38 & 1228 & Nerol & 0,33 & 0,43 & 0,53 & $1,2,3$ \\
\hline 39 & 1239 & Cumin aldehyde & 0,28 & 0,09 & 0,05 & $1,2,3$ \\
\hline 40 & 1242 & Carvone & 0,09 & - & - & $1,2,3$ \\
\hline 41 & 1243 & Hexyl isovalerate & - & 0,08 & 0,10 & $1,2,3$ \\
\hline 42 & 1257 & Linalyl acetate & 15,72 & 20,35 & 29,14 & $1,2,3$ \\
\hline 43 & 1285 & Bornyl acetate & - & 0,08 & - & $1,2,3$ \\
\hline 44 & 1287 & Cumin alcohol & 0,13 & - & - & $1,2,3$ \\
\hline 45 & 1289 & Lavandulyl acetate & 2,73 & 0,37 & 2,20 & $1,2,3$ \\
\hline 46 & 1331 & Hexyl tiglate & - & - & 0,21 & $1,2,3$ \\
\hline 47 & 1365 & Neryl acetate & 0,50 & 0,66 & 0,83 & $1,2,3$ \\
\hline 48 & 1383 & Geranyl acetate & 0,93 & 1,34 & 1,56 & $1,2,3$ \\
\hline 49 & 1418 & $\beta$-Caryophyllene & 2,04 & 0,91 & 0,55 & $1,2,3$ \\
\hline 50 & 1420 & $\alpha$-Santalene & 0,35 & 0,09 & - & 2,3 \\
\hline 51 & 1436 & trans- $\alpha$-Bergamotene & 0,11 & 0,03 & - & 2,3 \\
\hline 52 & 1454 & $\alpha$-Humulene & 0,06 & - & - & $1,2,3$ \\
\hline 53 & 1458 & $\beta$-Farnesene & 0,07 & 0,25 & 0,35 & 2,3 \\
\hline 54 & 1480 & Germacrene-D & 0,24 & 0,30 & 0,23 & 2,3 \\
\hline 55 & 1508 & $\alpha$-Farnesene & - & - & 0,03 & 2,3 \\
\hline 56 & 1581 & Caryophyllene oxide & 0,31 & 0,13 & 0,07 & $1,2,3$ \\
\hline 57 & 1640 & $\tau$-Cadinol & 0,06 & 0,06 & 0,08 & 2,3 \\
\hline 58 & 1653 & $\alpha$-Cadinol & - & 0,03 & 0,01 & 2,3 \\
\hline 59 & 1683 & $\alpha$-Bisabolol & - & 1,63 & 1,09 & $1,2,3$ \\
\hline
\end{tabular}

3) as final confirmation of the peak identification by GC/MS comparing their spectra with those in a commercial library Mass Spectra Database Newterp and NIST 98. The analysis was performed on a fused silica column DB-5, 30m x $0.25 \mathrm{~mm}$ i.d., film thickness $0.25 \mu \mathrm{m}$ (J \& W Scientific Inc., Rancho Cordova, California, USA) using a Gas Chromatograph 17A Ver. 3 interfaced with a Mass Spectrometer Shimadzu QP-5050A supported by the Class 5000 software. Injection temperature: $260^{\circ}$; interface heating: $300^{\circ}$; ion source heating: $200^{\circ}$; EI mode: $70 \mathrm{eV}$; scan range: $41-450 \mathrm{amu}$; and scan time $0.50 \mathrm{~s}$. Oven temperature programmes: a) $55^{\circ}-120^{\circ} \mathrm{C}\left(3^{\circ} / \mathrm{min}\right), 120-200^{\circ} \mathrm{C} 4^{\circ} / \mathrm{min}$, $200-220^{\circ}\left(6^{\circ} / \mathrm{min}\right)$ and $220^{\circ}$ for $5 \mathrm{~min}$ and b) $60-240^{\circ}$ at $3^{\circ} \mathrm{C} / \mathrm{min}$, carrier gas $\mathrm{He}, 54.8 \mathrm{kPa}$, split ratio $1: 30$. 
Table 2. Significant compounds and their percentages in the essential oils from Lavandula angustifolia and of the hybrids "Super" and "Special" from Greece

\begin{tabular}{|c|c|c|c|}
\hline Constituents & L. angustifolia & "Super" & "Special" \\
\hline & \multicolumn{3}{|c|}{ Percentage yield } \\
\hline 1,8 Cineol & 0,66 & 15,85 & 5,39 \\
\hline Linalool & 50,63 & 23,01 & 37,69 \\
\hline Camphor & 0,06 & 11,35 & 5,03 \\
\hline Borneol & 0,34 & 1,29 & 1,71 \\
\hline Linalyl acetate & 15,72 & 20,35 & 29,14 \\
\hline Nerol & 0,33 & 0,43 & 0,53 \\
\hline Neryl acetate & 0,5 & 0,66 & 0,83 \\
\hline Geranyl acetate & 0,93 & 1,34 & 1,56 \\
\hline Rhodinol fraction & 1,76 & 2,43 & 2,92 \\
\hline
\end{tabular}

\section{References:}

1. Buckle J., (1993), Acta Horticulturae 332: 253

2. Lis-Balchin M., Deans St. G., Eaglesham E. (1998), Flav. Fragr. J. 13: 98

3. Terblanche F. C., Kornelius, G. (2000), J. Essent. Oil Bearing Plants 3: 45

4. Wichtl M. (1984), Teedrogen, Wissenschaftliche Verlags-GmbH, Stuttgart, p. 207

5. Juvin P. (1979), Seifen-Ole-Fette-Wachse 10: 285

6. Lamparsky D. (1986), Perf. Flav. 11: 7

7. Kustrak D., Besik J. (1975), Pharm. Acta Helv. 50: 373

8. Ziolkowsky B. (1978), Seifen-Ole-Fette-Wachse 15: 421

9. Porter N.G., Shaw M.L., Hurndell L.C. (1982) New Zeal. J. of Agric. Res., 25, 389-324

10. Adams R.P (1995) Identification of Essential Oil Components by Gas Chromatography/Mass Spectrometry, Allured Publications

11. Lalande, B. (1984), Perf. Flav., Vol. 9 (2), 117-121

12. Tucker A. O., Maciarrello M. J., Howell J. T. (1984), Perf. Flav 9: 49

13. Naef, R., Morris A.F (1992) Rivista Ital. EPPOS (Numero Speciale), 364-377

14. Lawrence B. M. (1987-88), Perf. Flav. 12: 6, 59

15. Bernard, T., Perineau, F., Delmas, $M$ and Gaset, A (1989) J.Ess. Oil Res., Vol.1:261-267

16. Melegari M., Albasini A., Vampa G., Rinaldi M., Pecorari P., Bianchi A. (1981), Rivista Ital. 58: 314

17. Piccaglia R., Marotti M. (1993), Flav. Fragr. J. 8: 115

18. Katsiotis S. T. (1988), Flav. Fragr. J. 4: 221 